\title{
Constant Tension Characteristic Analysis and Experimental Verification of Passive Compensation Device
}

\author{
Zhiqiang $\mathrm{Xu}$, Wanli Li, and Zhixin Chen
}

\begin{abstract}
The tension study of accumulator is a critical factor in designing hydraulic system. The accumulator regarded as air spring when connected with cylinder plays the role of shock absorption and energy storage. Based on the luffing mechanism of crane, this paper structures mathematical model of accumulator-cylinder, simulates and analyzes the frequency response characteristics of the accumulator, and verifies the constant tension characteristics in experiments. The results show that the volume of accumulator decides the compensation effect. But no matter how large the volume of accumulator is, complete compensation could not be achieved. The comparison between system pressure and the boom motion shows the superior constant tension characteristic of the accumulator.
\end{abstract}

Index Terms-Accumulator, constant tension, experimental verification, mathematical model.

\section{INTRODUCTION}

Crane is the key lifting equipment of ship. In the process of lifting cargo on the ship, the crane's operation ability is greatly limited due to the influence of ship's swaying. For this reason, we design a device with wave compensation function by using the cushioning mechanism of accumulator to reduce the influence of wave, as shown in Fig. 1. Domestic and foreign research mainly focuses on how to control the ship attitude to reduce the impact of waves, but there is no research on the designed device. In this study, the mathematical model of the device is established and the simulation analysis is carried out. In addition, the test is the key process to study the tension of wire rope and the law of accumulator, which provides a reliable reference for the design, selection and device control [1]-[3]. The accumulator is an important auxiliary part of hydraulic system, which has been widely used in the design of energy-saving and vibration-absorbing system. It plays a key role in hydraulic system of crane luffing system because of excellent damping property. Scholars have established the basic theory of accumulator, but the existing analysis and research are mostly focus on energy-saving efficiency analysis, which deviates greatly from the actual application [4]-[8]. In this paper, the accumulator is simplified as air spring connected with cylinder, as shown in Fig. 1. The anti-impact

Manuscript received June 11, 2019; revised September 9, 2019.

Zhiqiang Xu and Wanli Li are with the School of Machinery and Energy Engineering, Tongji University, Shanghai 201804, China (e-mail: xuzhiqiang@fmiri.ac.cn, cnlwl@tongji.edu.cn).

Zhixin Chen is with the Fishery Machinery and Instrument Research Institute, Chinese Academy of Fishery Sciences, Shanghai 20092, China (e-mail: chenzhixin@fmiri.ac.cn). performance of the air spring model is studied by constructing mathematical model and experiments. The conclusions provide helpful reference for the design of electro-hydraulic control system and selection of hydraulic components [9].

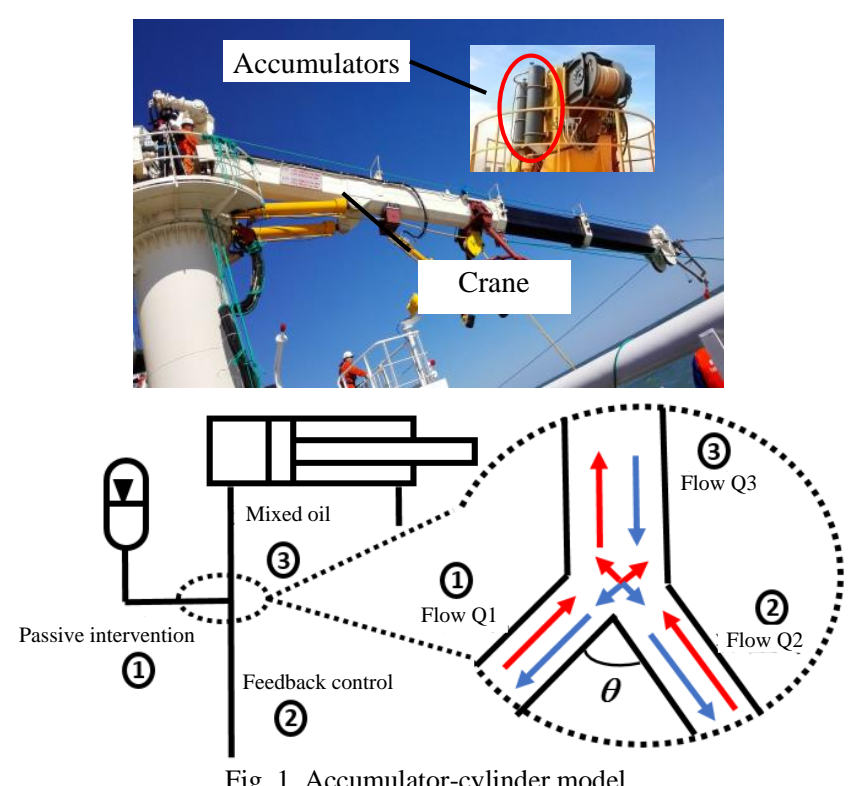

The passive compensation device includes accumulator and hydraulic cylinder. The oil chamber of the accumulator is connected with the rodless chamber of the cylinder, so the oil flowed into the cylinder is from the valve and the accumulator simultaneously [10]-[13]. When the valve operates, the oil flowed out of the rod chamber can be stored in the accumulator.

\section{MODEL BUILDING}

\section{A. Crane Model}

The boom luffing system is simplified as a second-order spring-damping system, as shown in Fig. 2. The accumulator can be seen as a spring [14]. The spring stiffness is related to the accumulator volume and the inflatable pressure [15]-[19]. Force equation of the boom is shown in (1).

$$
J \ddot{\alpha}_{1}+c\left(\dot{\alpha}_{1}-\dot{\alpha}_{o}\right) \sin ^{2} \alpha_{N} l_{1}^{2}+k\left(\alpha_{1}-\alpha_{o}\right) \sin ^{2} \alpha_{N} l_{1}^{2}=\mathbf{0}
$$

$J$ denotes rotary inertia of boom, $J=\frac{\mathbf{1}}{\mathbf{3}} m \cdot l_{\mathbf{3}}{ }^{2}, \mathrm{~m}$ denotes mass of boom; c denotes damping coefficient of cylinder; $l_{3}$ denotes length of boom; c denotes damping coefficient of cylinder; $\alpha 1$ denotes rotary angle of boom; $\alpha_{0}$ denotes rotary 
angle of base, $\alpha_{0=} \alpha_{\mathrm{m}} \cdot \sin (\omega \mathrm{t}), \alpha_{\mathrm{m}}$ denotes amplitude of base, $\omega$ denotes vibration frequency of base; $\alpha_{N}$ denotes angle between cylinder and boom; $\mathrm{k}$ denotes elastic coefficient.
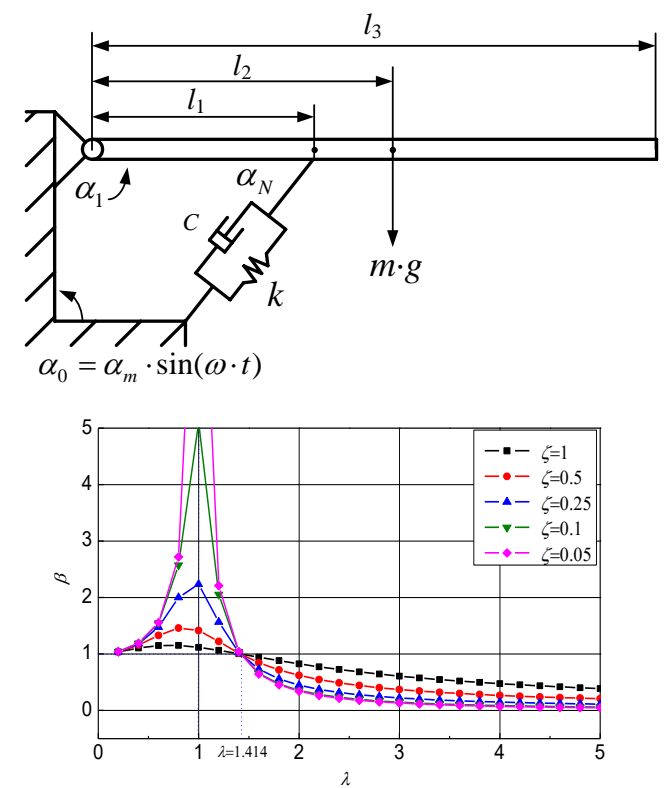

Fig. 2. Vibration model and amplitude frequency response of boom.

The amplification factor of the harmonic vibration of the boom obtained from (1).

$$
\beta=\sqrt{\frac{1+(2 \zeta \lambda)^{2}}{\left(1-\lambda^{2}\right)^{2}+(2 \zeta \lambda)^{2}}}
$$

$\lambda=\omega / \omega_{n}, \omega_{n}$ denotes natural frequency, $\omega_{n}=\sqrt{\frac{k \cdot l_{1}}{J}} ; \zeta$ denotes damping ratio, $\zeta=\frac{c}{2} \sqrt{\frac{l_{1}}{J \cdot k}}$.

The amplitude frequency response curve of the boom show the feedback effects of accumulator are not all positive, decided by the stiffness and damping of the device. When $\lambda<1.414$, the accumulator is fails to absorbing vacation, conversely, enlarges the rolling of boom, especially near the resonance region of $\lambda=1$. Therefore, the cylinder parameters and accumulator charging pressure are needed to be selected properly.

\section{B. Accumulator Model}
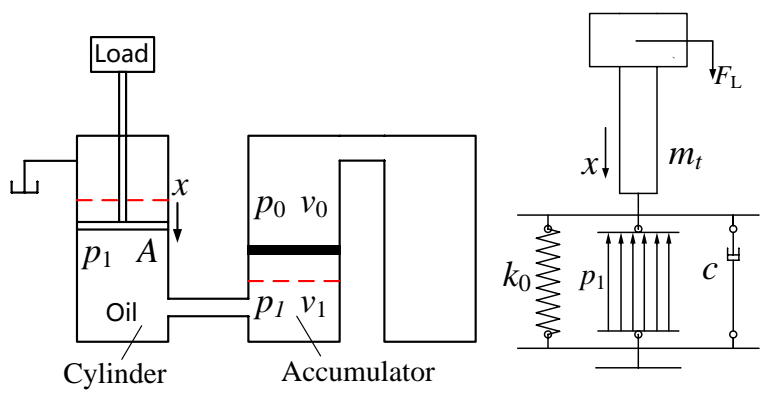

Fig. 3. Simplified model of accumulator.

Connecting the accumulator with cylinder, the whole device is simplified as a spring system [20]. The simplified model of accumulator is shown in Fig. 3.

$$
m_{t} \cdot \ddot{x}+\mathbf{c} \cdot \dot{\mathbf{x}}+k_{\mathbf{0}} \cdot x=F_{L}-p_{1} \cdot A
$$

$F_{L}$ denotes load of cylinder; $k_{0}$ denotes elastic coefficient of piston rod; $\mathrm{m}_{\mathrm{t}}$ denotes the mass of the piston rod; $A$ denotes the action area of the cylinder.

$p_{0} v_{0}{ }^{n}=p_{1} v_{1}{ }^{n}, v_{0}$ denotes volume of the accumulator, $v_{1}$ denotes working volume, $\mathrm{n}$ denotes the index factor of gas state equation, then $v_{1}=v_{0}+x \cdot A ; x$ denotes displacement of cylinder. Equator (4) can be got.

$$
p_{1}=p_{0}\left(\frac{v_{0}}{v_{0}+x A}\right)^{n}
$$

$p_{1}$ denotes stable pressure of accumulator

$$
\left(\Delta p=p_{1}-p_{0}\right) .
$$

Combine (3) and (4) to obtain (5).

$$
F_{L}=m_{t} \cdot \ddot{x}+c \cdot \dot{x}+p_{0} \cdot A \cdot\left(\frac{v_{0}}{v_{0}+x \cdot A}\right)^{n}
$$

According to the requirements of adiabatic process, the equation $p \cdot v^{\mathrm{n}}=$ constant is satisfied.

Set $\left(p_{0}, v_{0}\right)$ as initial gas pressure and volume, $\left(p_{1}, v_{1}\right)$ is another state, the accumulator's gas adiabatic equation is:

$$
\begin{gathered}
p_{0} \cdot v_{0}{ }^{n}=p_{1} \cdot v_{1}{ }^{n} \\
\ln p_{0}+n \cdot \ln v_{0}=\ln p_{1}+n \cdot \ln v_{1} \\
n=\frac{\ln p_{1}-\ln p_{0}}{\ln v_{0}-\ln v_{1}}
\end{gathered}
$$

$n$ values in gas state equation is greatly influenced by the outside conditions, through the experiment, testing 5 groups data, then insert the data into equation (8) to get $n$ value, as shown in Table I.

\begin{tabular}{c|ccccc}
\multicolumn{7}{c}{ TABLE I: ACCUMULATOR's SAMPLE VALUES } \\
\hline Number & 1 & 2 & 3 & 4 & 5 \\
\hline Pressure & 43.656 & 48.560 & 39.085 & 46.842 & 42.473 \\
\hline Result & 1.192 & 1.2924 & 1.3387 & 1.1727 & 1.1765 \\
\hline
\end{tabular}

Draw the value of $\mathrm{n}$ value in gas adiabatic equation. The value of $\mathrm{n}$ is time-varying, range from 1.1 to 1.5 , and take the average result: $n=1.35$.

The simulation of the system is carried out in MATLAB/Simulink [21]-[24], and the simulation model is shown in Fig. 4.

Based on the above equation (5), use MATLAB/Simulink function to establish the system's simulation model about tension and displacement, shown in Fig. 4. The Sine Wave module is used as the load's movement, its amplitude is $15^{\circ}$, and period is $10 \mathrm{~s}$.

The vibration of the boom base is defined as a sine wave with a period of $10 \mathrm{~s}$ and $15^{\circ} . m_{t}=6.3 \mathrm{~kg} ; c=0.1 \mathrm{~N} \mathrm{~s} / \mathrm{m}$; $A=0.0078$ (cylinder's diameter is $100 \mathrm{~mm}$ ); $v_{0}=6.3 \mathrm{~L}$; $p_{0}=6.0 \mathrm{MPa}$.

Conclusions:

1) The amplitude of the boom is significantly lower than the ship.

2) With the increasing of volume, the component effect increases greatly, but no matter how large the volume of accumulator is, full compensation could not be achieved. 
3) The pressure change of the accumulator displaying opposed way with the load displacement shows the constant tension characteristic clearly.
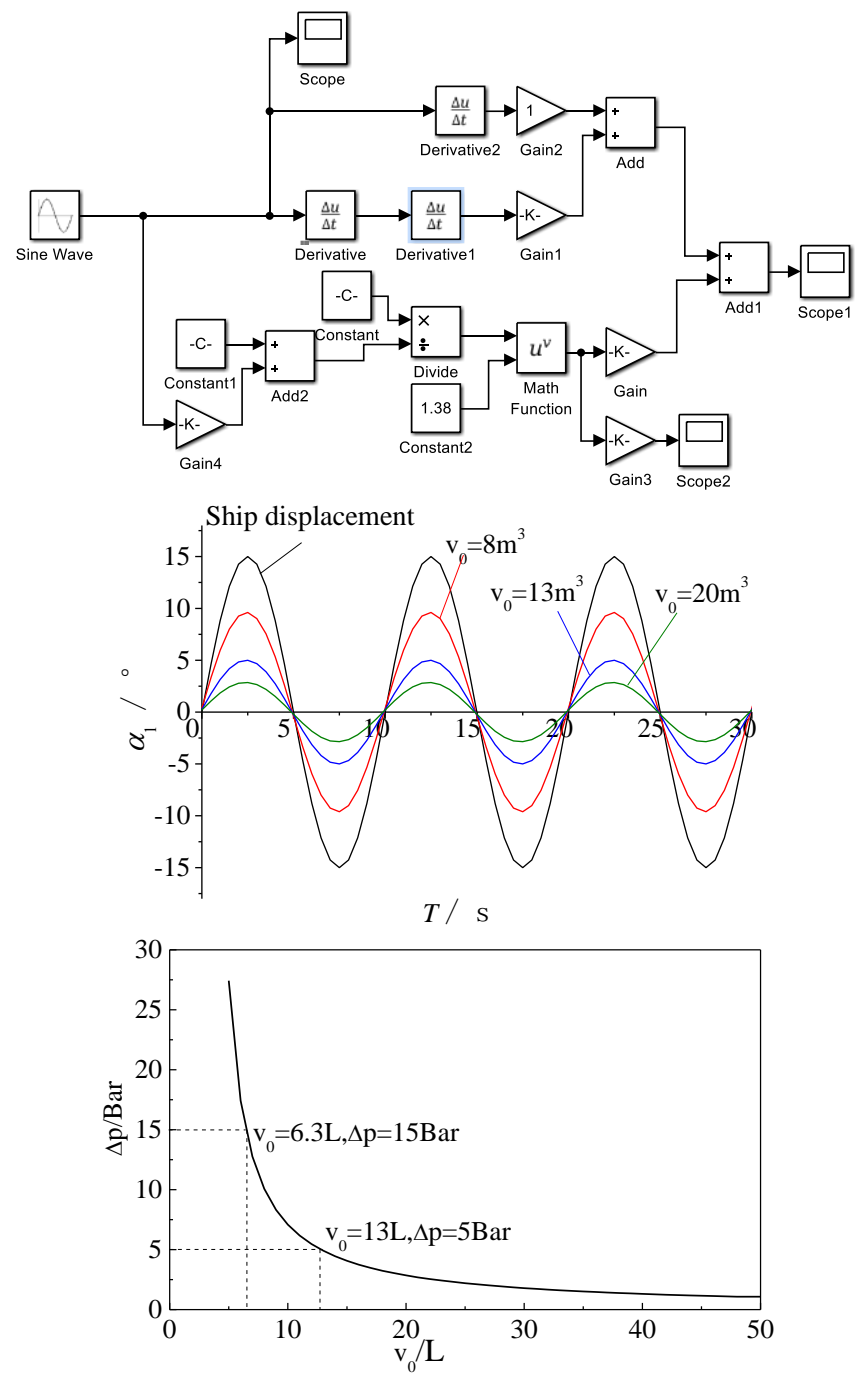

Fig. 4. Simulation model and results.

\section{Hydraulic System Model}

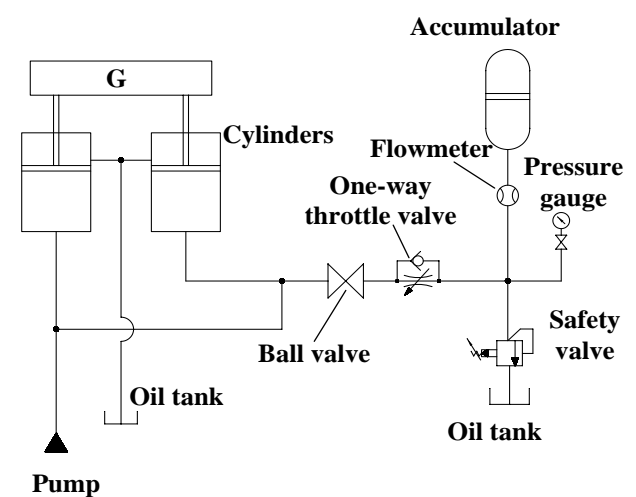

Fig. 5. Hydraulic system diagram.

The hydraulic system circuit of passive compensation device is constructed, as shown in Fig. 5. The hydraulic system includes the cylinder, accumulator, pump, tank, safety valve, flowmeter, pressure gauge, ball valve and one-way throttle valve. When gravity drops, the hydraulic oil flow from the rodless chamber of the cylinder to the accumulator through the ball valve and one-way throttle valve. When the cylinder extends, the hydraulic oil enters the rodless chamber of the cylinder from the accumulator. When the cylinder extending, the main hydraulic circuit and accumulator together supply oil to the crane cylinder to improve the action of the cylinder [25]. A switch ball valve and a one-way throttle valve are arranged in the oil cavity passage of the rodless cylinder and accumulator. When passive compensation device is needed, the ball valve is opened. The one-way throttle valve is adjusted to change the elastic stiffness of the accumulator so as to jump out of the resonance region and improve the compensation effect. The safety valve ensures the unloading oil pressure when the system pressure is on the high side, and guarantees the best passive performance.

When the cylinder retracts, the swing energy of the ship is recovered into the accumulator by means of the gravity load of the boom. On the one hand, the vibration shock is alleviated, on the other hand, the energy is accumulated for the reverse action of the cylinder to reduce the energy consumption of the system.

\section{EXPERIMENTAL VERIFICATION}

\section{A. Hydraulic Equipment}

The trial-produced equipment model is shown in Fig. 6. The model is fixed on the rocking test bench, which is supported by four servo cylinders. The different sea conditions can be simulated by changing the frequency and speed of the bench [26], [27]. The simulation platform can generate sine vibration with the trends: front and back, left and right, up and down.

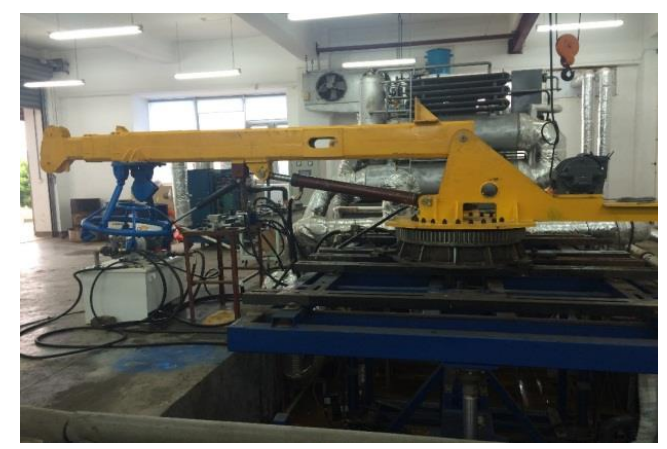

Fig. 6. Wave simulation experiment platform.

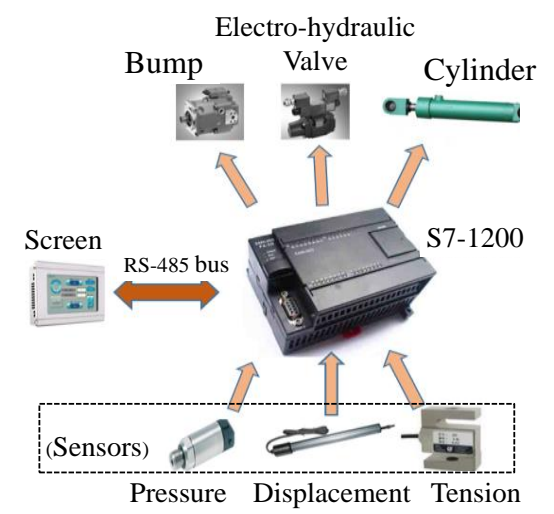

Fig. 7. Control system's hardware connection.

This system chooses Huba Control company's 511 type pressure tension, and displacement sensors, which were used 
to collect the pressure of the accumulator, wire rope tension and the displacement [28]. The system selects Siemens S7-200 programmable controller, through the input/output interface the system controller is connected to the sensors and hydraulic components to get real-time data; via Ethernet, the system controller and PC exchange information. Fig. 7 is the hardware connection diagram.

The PLC outputs 4-20mA current signal, which is used to control the valve through proportional amplifier. The angle and displacement sensors are applied to reflect the cylinder's movements [29]-[31].

\section{B. Data Collecting}

The experimental process could be divide into three periods: T1, T2, T3. Controlling the amplitude and frequency of bench, the data are collected by using tension angle and displacement sensors [32]-[35]. The whole data are shown in Fig. 8.

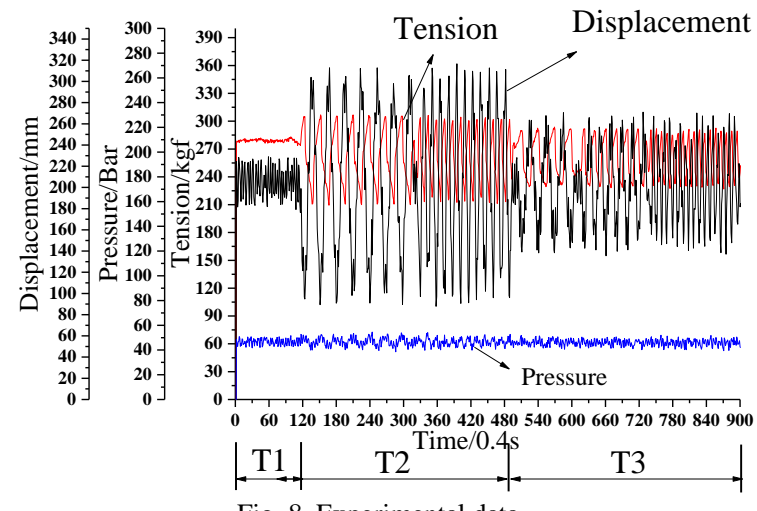

Fig. 8. Experimental data.

The experimental data collecting frequency is $40-80 \mathrm{~s} / \mathrm{min}$, so the experimental data express the whole information of test according to the sampling theorem.

\section{Data Analyzing}

The constant tension characteristics of accumulator are studied by analyzing data under different periods.

(1)Stage T1: $0 \mathrm{~s}-120 \mathrm{~s}$

Controlling the displacement of test bed at $50 \mathrm{~mm}$, the result shows that accumulator's pressure stay stable at 45Bar, tension fluctuation is small. According to the data shown in Fig. 9, pressure will be stable enough as the displacement range is less than $50 \mathrm{~mm}$.

\section{(2) Stage T2: $120 \mathrm{~s}-510$ seconds}

The displacement of the test bed is controlled in the range of $200 \mathrm{~mm}$. In 120s 350s, the movement cycle is $12 \mathrm{~s}$, and $6 \mathrm{~s}$ in $350 \mathrm{~s} \sim 510 \mathrm{~s}$. The data show that the tension difference of wire rope is $80 \mathrm{kgf}$ around $260 \mathrm{kgf}$, and the accumulator pressure difference is $15 \mathrm{Bar}$. Conclusion: The tension of wire rope and the pressure of accumulator change periodically with the bench motion. The change trend of tension and pressure is opposite to displacement. The tension and pressure are at valley as the displacement is at peak and vice versa.

\section{(3) Stage T3:510 s - 920 seconds}

The displacement of the bench is controlled in the range of $100 \mathrm{~mm}$. In $510 \mathrm{~s} \sim 650 \mathrm{~s}$, the movement cycle is $12 \mathrm{~s}$, and $8 \mathrm{~s}$ in $650 \mathrm{~s} \sim 740 \mathrm{~s}, 4 \mathrm{~s}$ in $740 \mathrm{~s} \sim 920 \mathrm{~s}$. The data show that the tension difference of wire rope is $60 \mathrm{kgf}$ around $260 \mathrm{kgf}$, and the accumulator pressure difference is 10Bar. Conclusion: The tension of wire rope and the pressure of accumulator change smaller as the bench motion are lower. The pre-change pressure of accumulator decides the even tension value of wire rope that is $260 \mathrm{kgf}$ in this test.

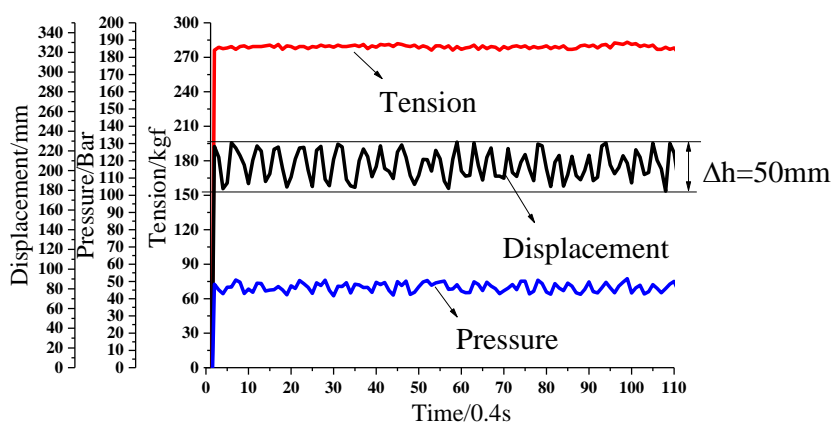

(a)Stage T1 Data

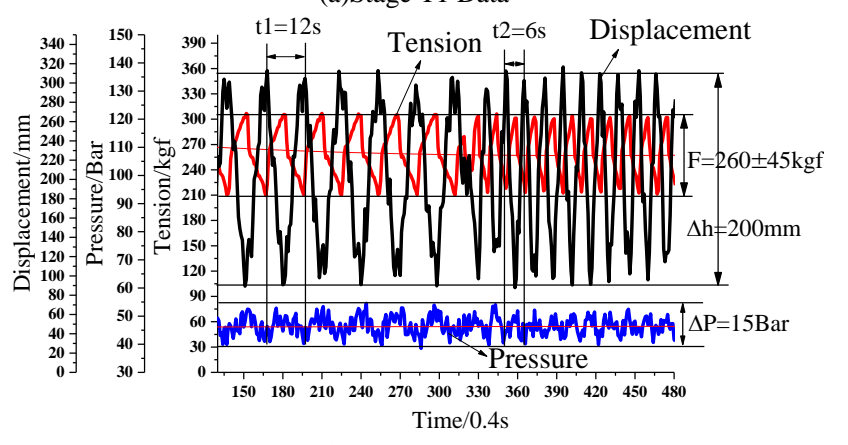

(b)Stage T2 Data

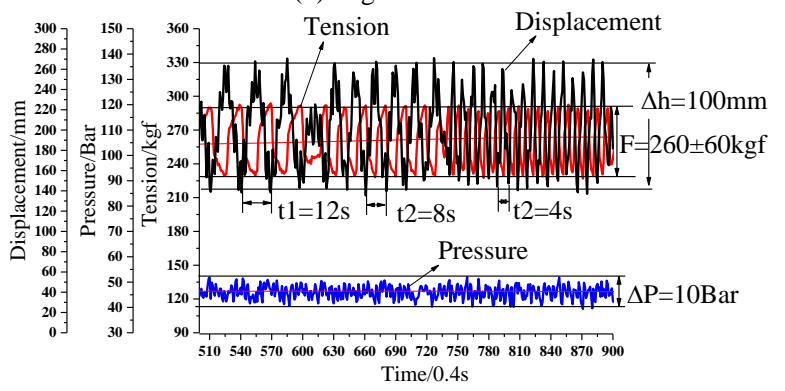

(c)Stage T3 Data

Fig. 9. Data collecting and analyzing.

\section{CONCLUSION}

Constant tension characteristics of accumulator are gotten by establishing the mathematic model, analyzing simulation and experimental data. It comes to some helpful references for the design of electro-hydraulic system and selection of components as following:

(1) The accumulator's pressure changes in opposite way against the bench moving.

(2) The accumulator's pressure increases with the displacement decreases, and can be stable enough when the displacement range is less than $50 \mathrm{~mm}$. The pressure change of the accumulator displaying opposed way with the displacement shows the constant tension characteristic clearly.

(3) The accumulator's pressure value is related to piston position and cross section area that is the larger area makes the lower pressure. The pre-change pressure of accumulator decides the even tension value of wire rope that is the tension of wire rope and the pressure of accumulator change smaller as the bench motion are lower. 


\section{REFERENCES}

[1] Y.-S. Lu, "Use of large-capacity piston accumulator," Hydraulic and Pneumatic, vol. 1, pp. 86-88, 2013.

[2] X. Z. Zheng and Y. G. Luo, "Configuration design and analysis of offshore mining compensation platform based on parallel mechanism," China Mechanical Engineering, vol. 18, pp. 1565-1567, 2014.

[3] S. Takagawa, A new Concept Design of Heave Compensation System for Longer Life of Cables, Tokyo: The University of Tokyo, pp. 123-135, 2015.

[4] J. Liu, Z. Hou, and X. Chen, "Experimental and numerical study on the aero-heating characteristics of blunted wave rider," Applied Thermal Engineering, vol. 1, pp. 301-314, 2013.

[5] M. Lobbia and K. Suzuki, "Multidisciplinary design optimization of hypersonic transport configurations using wave riders," AIAA Paper. vol. 1, pp. 2014-2359, 2014.

[6] T. Hung, K. Ahn, "Modeling and simulation of hydrostatic transmission system with energy regeneration using hydraulic accumulator," Journal of Mechanical Science and Technology, vol. 15 , pp. 1163-1175, 2010.

[7] L. Lu and B. Yao, "Energy-saving adaptive robust control of a hydraulic manipulator using five cartridge valves with an accumulator," IEEE Transactions on Industrial Electronics, vol. 1, pp. 7046-7054, 2014.

[8] T. Lin, W. Huang, and H. Ren, "New compound energy regeneration system and control strategy for hybrid hydraulic excavators," Automation in Construction, vol. 68, pp. 11-20, 2016.

[9] T. L. Lin, Q. Chen, and H. L. Ren, "Energy regeneration hydraulic system via a relief valve with energy regeneration unit," Appl Sci-Basel, vol. 7, pp. 21-30, 2017

[10] J. Siebert, M. Wydra, and M. Geimer, "Efficiency improved load sensing system-reduction of system inherent pressure losses," Energies, vol. 7, pp. 111-120, 2017.

[11] H. Kogler and R. Scheidl, "Energy efficient linear drive axis using a hydraulic switching converter," J Dyn Syst-T Asme, vol. 9, pp. 138-145, 2016.

[12] F. Yoshida, S. Iio, and K. Ito, "Experimental and theoretical analysis of active charge accumulator for water hydraulics system," IEEE Access, vol. 5, pp. 881-908, 2017.

[13] J. Yang, "Yantai salvage bureau," Feasibility Study Report on Large-scale Salvage Lifting Engineering Vessels, 2009.

[14] S. Kuchler, T. Mahl, J. Neupert, K. Schneider, and O. Sawodny, "Active control for an offshore crane using prediction of the vessel's motion," IEEE-ASME Transactions on Mechatronics, vol. 16, no. 2, pp 297-309, 2011

[15] Y. Sun, W. Li et al., "Dynamics analysis and active control of a floating crane," Tehnicki Vjesnik, vol. 22, no. 6, pp. 1383-1391, 2015.

[16] Y. Hu, L. Tao, and W. Lv, "Anti-pendulation analysis of parallel wave compensation systems," Proceedings of the Institution of Mechanical Engineers, Part M: Journal of Engineering for the Maritime Environment, vol. 230, no. 1, pp. 177-186, 2016.

[17] S. Wang, Y. Sun, H. Chen et al., "Kinematics and force analysis of a novel offshore crane combined compensation system," Proceedings of the Institution of Mechanical Engineers, Part M: Journal of Engineering for the Maritime Environment, vol. 231, no. 2, pp. 633-648, 2017.

[18] Y. G. Sun, H. Y. Qiang, J. Q. Xu et al., "The nonlinear dynamics and anti-sway tracking control for offshore container crane on a mobile harbor," Journal of Marine Science and Technology, vol. 25, no. 6, pp. 656-665, 2017

[19] K. Takagi and H. Mishimura, "Control of a jib-type crane mounted on a flexible structure," IEEE Trans. Control Syst. Technol., vol. 11, no. 1 , pp. 32-42, 2003.

[20] N. Sun, Y. C. Fang, H. Chen, Y. M. Fu, and B. Lu, "Nonlinear stabilizing control for ship-mounted cranes with ship roll and heave movements: Design, analysis, and experiments," IEEE Transactions on Systems, Man, and Cybernetics: Systems, vol. 48, no. 10, pp. 1781-1793, 2018.

[21] K. Huhtala et al., "Model-based force and position tracking control of an asymmetric cylinder with a digital hydraulic valve," International Journal of Fluid Power, pp. 1-10, 2016.

[22] P. Y. Wang, Q. N. Wang, A. P. Hu, and Y. B. Yu, "Analysis of regenerative brake system of hybrid bus based on simulink-AMESim co-simulation," Jilin Daxue Xuebao, vol. 38, pp. 7-11, 2008.
[23] G. H. Fang, J. Hu, and X. C. Wang, "Accumulator absorb shocks simulation analysis on pavement hydraulic power system," Advanced Materials Research, pp. 924-927, 945-949, 2014.

[24] S. Ingar, A. Landet, O. M. Pavlov et al., "Control of heave-induced pressure fluctuations in managed pressure drilling," IEEE Transactions on Control Systems Technology, vol. 21, no. 4, pp. 1340-1351, 2013.

[25] E. Kilic, M. Dolen, A. B. Koku et al., "Accurate pressure prediction of a servo-valve controlled hydraulic system," Mechatronics, vol. 22, no. 7, pp. 997-1014, 2012.

[26] Q. Ma, X. D. Kong, and J. Yao, "Research of the influence factors of the accumulator fast forging hydraulic control system," in Proc. 2010 IEEE International Conference on Automatic and Logistics, Shatin, Hong Kong, pp. 414-417, Aug. 16-20, 2010.

[27] D. Liu, W. Guo, and J. Yi, "Dynamics and GA-based stable control for a class of underactuated mechanical systems," International Journal of Control, Automation, and Systems, vol. 6, no. 1, pp. 35-43, 2008.

[28] J. Ran et al., "Adaptive robust control of quadrotor with a 2-degree-of-freedom robotic arm," Advances in Mechanical Engineering, vol. 10, no. 8, p. 1687814018778639, 2018.

[29] S. K. Wang, J. M. Peng, J. Z. Wang et al., "Hybrid control strategy research based on pump and valve cooperate system in parallel," Transactions of Beijing Institute of Technology, vol. 35, no. 4, pp. 397-402, 2015.

[30] A. K. Yadav, P. Gaur, and P. Saxena, "Robust stability analysis of PMSM with parametric uncertainty using kharitonov theorem," Journal of Electrical Systems, vol. 12, no. 2, pp. 258-277, 2016.

[31] L. Liu, S. Dong, Y. Wang et al., "Clearance of flight control law based on structural singular value theory," IEEE Transactions on Aerospace and Electronic Systems, vol. 51, no. 3, pp. 2138-2147, 2015.

[32] Y. Sun, J. Q. Xu et al., "An optimal performance based new multi-objective model for heat and power hub in large scale users," Energy, vol. 161, pp. 1234-1249, 2018.

[33] Z. C. Qiu, M. L. Shi, B. Wang et al., "Genetic algorithm based active vibration control for a moving flexible smart beam driven by a pneumatic rod cylinder," Journal of Sound \& Vibration, vol. 331, no. 10, pp. 2233-2256, 2012.

[34] L. B. Sheng, J. S. Ma, H. Y. Sun et al., "The effect of accumulator volume and inflation pressure on tracked vehicle braking system,' Applied Mechanics \& Materials, pp. 184-185, 780-783, 2012.

[35] W. Wu, J. Hu, C. Jing et al., "Investigation of energy efficient hydraulic hybrid propulsion system for automobiles," Energy, vol. 73 , no. 9, pp. 497-505, 2014

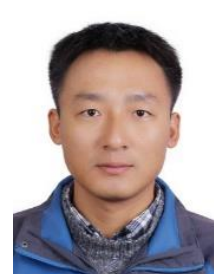

Zhiqiang Xu received his B.S. degree in 2006 and M.S. degree in 2009 in mechatronics engineering from Tongji University, China. He is currently working toward the Ph.D. degree in mechatronics engineering in Tongji University, China. His current research interests include hydraulic machinery, dynamic systems and intelligent control.

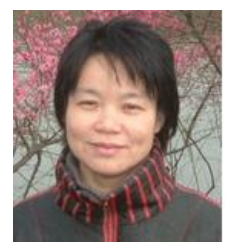

Wanli Li received her B.S. degree and M.S. degree in mechatronics engineering from Dalian University of Technology, Dalian, China. She received her Ph.D. degree in mechanical engineering from Tongji University, China. She has been a professor and doctoral tutor in Tongji University, China. Her current research interests include hydraulic machinery, maglev train and intelligent control.

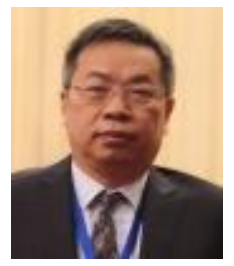

Zhixin Chen received the B.S. degree in mechatronics engineering from Shanghai ocean University, China and M.S. degree in mechatronics engineering from Tongji University, China. His current research interests include aspects of dynamic systems, artificial intelligence and non-linear control. 